\title{
Correction of Skeletal Sagittal Dysplasia using Twin Block Traction Technique
}

\author{
${ }^{1}$ Prateek Navratan Daga, ${ }^{2}$ Girish R Karandikar, ${ }^{3}$ VK Ravindranath, ${ }^{4}$ Sachin Doshi
}

\begin{abstract}
The primary concern of the patient as well as their parent seeking orthodontic treatment is the sagittal relationship of the dentition and jaws. Twin block is the most common functional appliance used successfully in correction of growing patient with skeletal class II malocclusion. However, the method of using extraoral traction in combination with twin block appliance (twin block traction technique) is to reinforce the functional component for correction of a class II sagittal relationship. A 12-year-old male patient reported to the Department of Orthodontics with a chief complaint of forwardly placed upper front teeth. With the help of clinical examination, cephalometrics, and diagnostic records, the diagnosis of the patient was confirmed as skeletal class II maxillomandibular relationship with prognathic maxilla and retrognathic mandible with a vertical growth pattern. The patient was treated with twin block appliance along with headgear. The appliance design and postfunctional results are demonstrated in the following case report. Although twin block with high-pull headgear is known to produce favorable results in mixed dentition, the same was observed in permanent dentition during growth phase. Combination of twin block appliance with high pull headgear gave the desired results.
\end{abstract}

Keywords: Extraoral traction, High-pull headgear, Skeletal class II, Twin block,

Howto cite this article: DagaPN, KarandikarGR, Ravindranath VK, Doshi S. Correction of Skeletal Sagittal Dysplasia using Twin Block Traction Technique. J Contemp Dent 2016;6(1): 75-79.

Source of support: Nil

Conflict of interest: None

\section{INTRODUCTION}

The primary concern of the patient as well as their parent seeking orthodontic treatment is the sagittal relationship of the dentition and jaws. The most commonly observed sagittal problems are skeletal class II maxillomandibular relationship, ${ }^{1}$ affecting about one-third of the examined patients seeking orthodontic treatment. ${ }^{2}$ Skeletal

\footnotetext{
${ }^{1}$ Postgraduate Student (3rd Year), ${ }^{2,3}$ Professor, ${ }^{4}$ Senior Lecturer

${ }^{1-4}$ Department of Orthodontics and Dentofacial Orthopedics MGM Dental College and Hospital, Navi Mumbai, Maharashtra India

Corresponding Author: Prateek Navratan Daga, Postgraduate Student (3rd Year), Department of Orthodontics and Dentofacial Orthopedics, Mahatma Gandhi Mission's Dental College and Hospital, Navi Mumbai, Maharashtra, India, Phone: +02228166295 e-mail: dr.prateekdaga@gmail.com
}

class II malocclusions occur due to various factors, such as maxillary protrusion, mandibular retrusion, or a combination of the aforementioned, together with abnormal dental relationships and profile discrepancy. ${ }^{3}$ McNamara ${ }^{4}$ reported mandibular retrusion to be the most common characteristic in a skeletal class II malocclusion.

Treatment modalities for a skeletal class II patient include various removable and fixed functional appliances to stimulate the mandibular growth by forward positioning of the mandible. ${ }^{5-8}$ Growth remodulation and/or redirection is possible only in growing patients. Adult patients suffering from skeletal class II problems are treated with fixed appliance alone or in combination with orthognathic surgery. However, the severity and the nature of dysplasia are the crucial factors in deciding the treatment modality. ${ }^{9}$

In most cases, twin block appliance without the need of an additional orthopedic or tractional force can help in achieving functional occlusion. Twin block appliance along with orthopedic traction is to be considered in cases wherein the response to functional correction is expected to be poor. However, this approach of using functional therapy with extraoral traction should be used in treating cases with severe malocclusion. The indication for functional therapy with orthopedic traction is confined to cases requiring intrusion and distalization of maxilla or maxillary dentition, in cases with vertical growth pattern requiring intrusion of posterior segment of maxilla, and in adult patients for correction of severe malocclusion. ${ }^{10,11}$

\section{CASE REPORT}

A 12-year-old male patient reported to Department of Orthodontics and Dentofacial Orthopedics with a chief complaint of forwardly placed upper front teeth. On extraoral examination, it was found that the patient had a convex profile, incompetent lips with an interlabial gap of $4 \mathrm{~mm}$, short upper lip length (14 $\mathrm{mm})$, acute nasolabial angle, receded chin and deep mentolabial sulcus, and vertical growth pattern. On intraoral examination, the case was classified as Angle's class II division I malocclusion with class II molar and canine relationship bilaterally with an increased overjet of $10 \mathrm{~mm}$ and overbite of $5.5 \mathrm{~mm}$. The pretreatment extraoral and intraoral photographs (Figs 1 and 2) were recorded. 


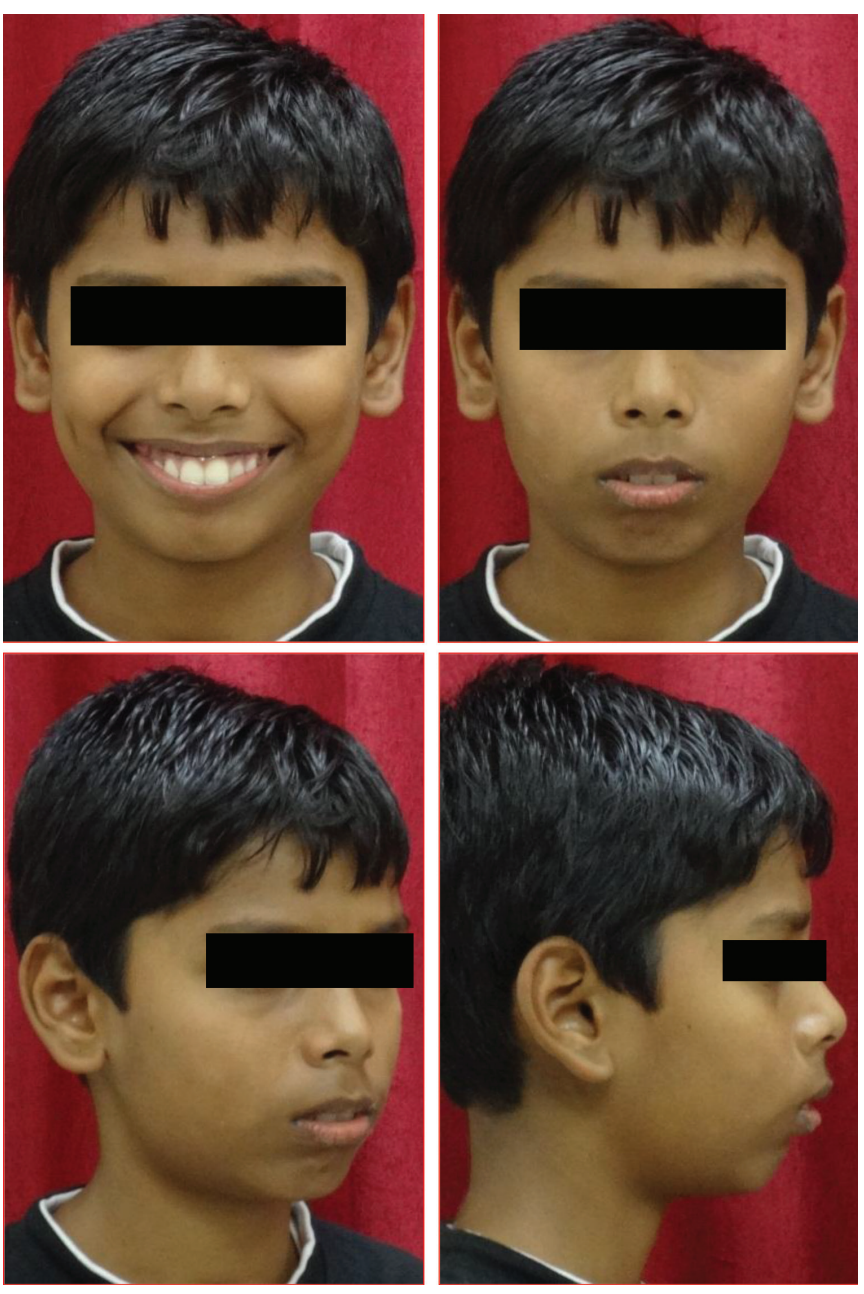

Fig. 1: Pretreatment extraoral photographs

The case was diagnosed as skeletal class II malocclusion with a combination of maxillary excess and mandibular deficiency. Cephalometric analysis showed skeletal class II sagittal relationship and vertical growth pattern. Evaluation of patient's cervical radiograph indicated considerable amount of growth remaining. The pretreatment lateral cephalogram is shown in Figure 3.

\section{TREATMENT OBJECTIVES}

- Correction of skeletal sagittal dysplasia (class II maxillomandibular relationship)

- Reduction in the convexity of profile

- Achievement of class I molar and canine relation

- Achievement of normal overjet and overbite.

\section{TREATMENT PLAN}

In order to correct the skeletal class II maxillomandibular dyplasia, restrict maxillary growth, and redirect mandibular growth, growth modification was planned using functional appliance. Twin block appliance with high pull headgear in the first stage followed by fixed orthodontics appliance for final finishing and detailing of occlusion.
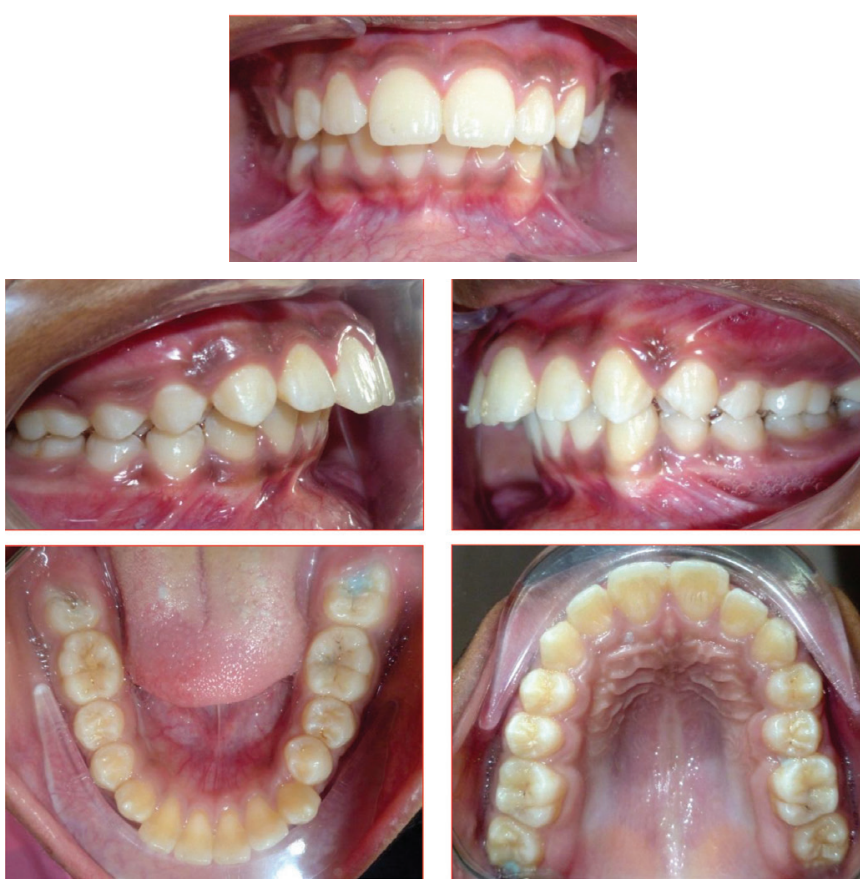

Fig. 2: Pretreatment intraoral photographs

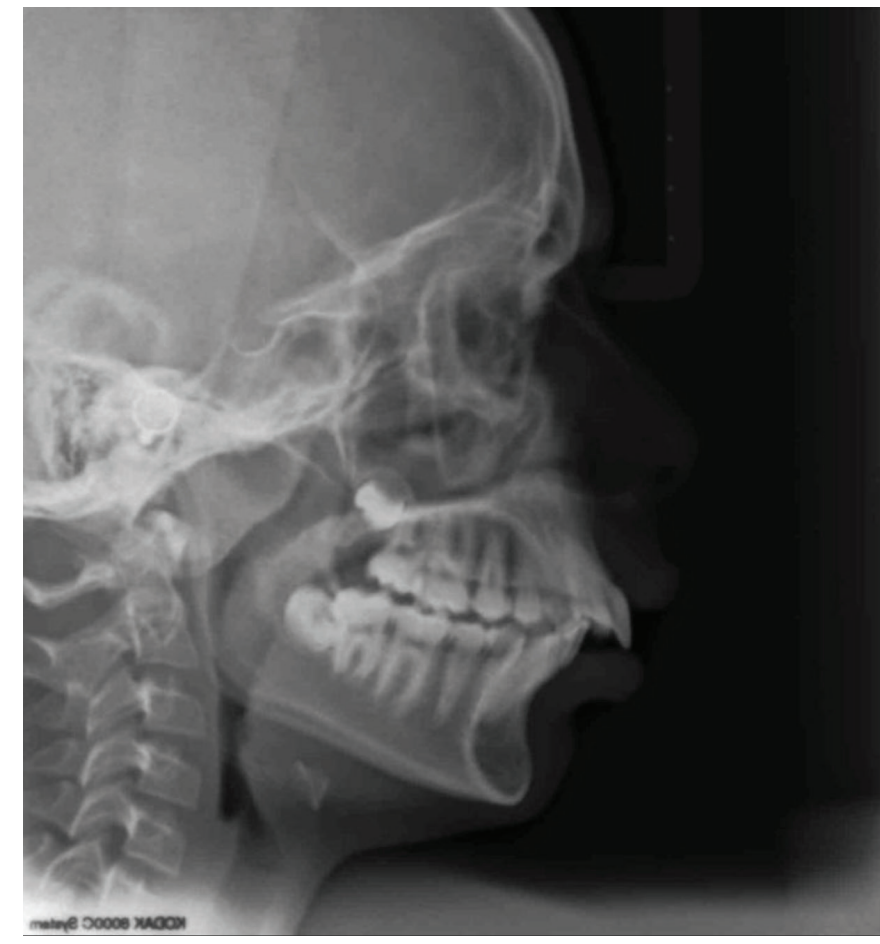

Fig. 3: Pretreatment lateral cephalogram

Twin block appliance with headgear tubes and capping of lower incisors to prevent flaring along with high pull headgear was worn for a period of 14 months (Figs 4 and 5). Remarkable correction in sagittal skeletal dysplasia along with achievement of class I molar and canine relation bilaterally with significant reduction in overjet and overbite was observed. Postfunctional extraoral and intraoral photographs are shown in Figures 6 and 7. The improvement in profile is shown in Figure 8. Skeletal 

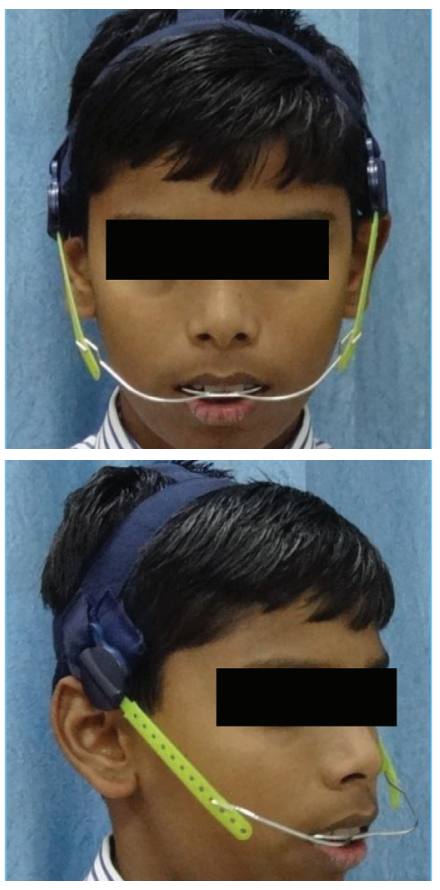

Fig. 4: Mid treatment extraoral photographs
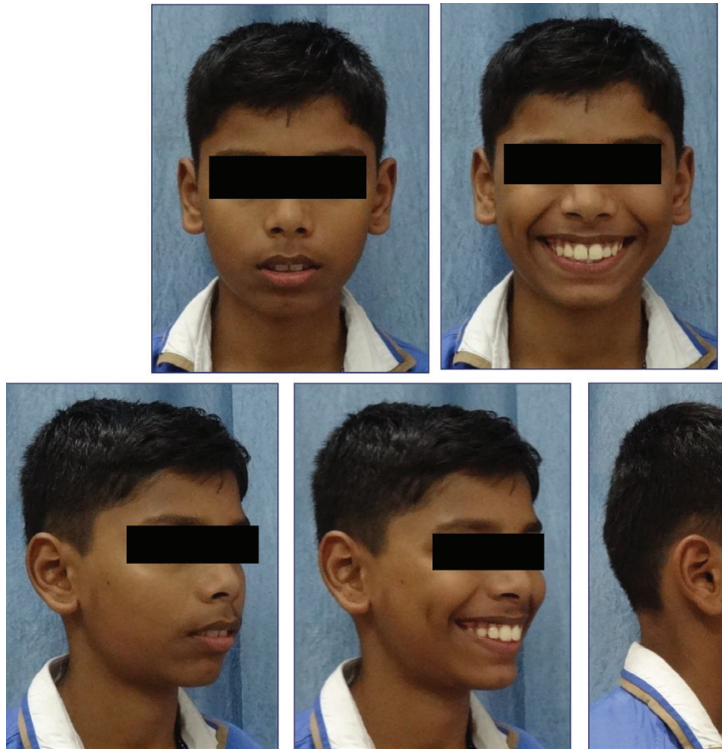

Fig. 6: Postfunctional extraoral photographs
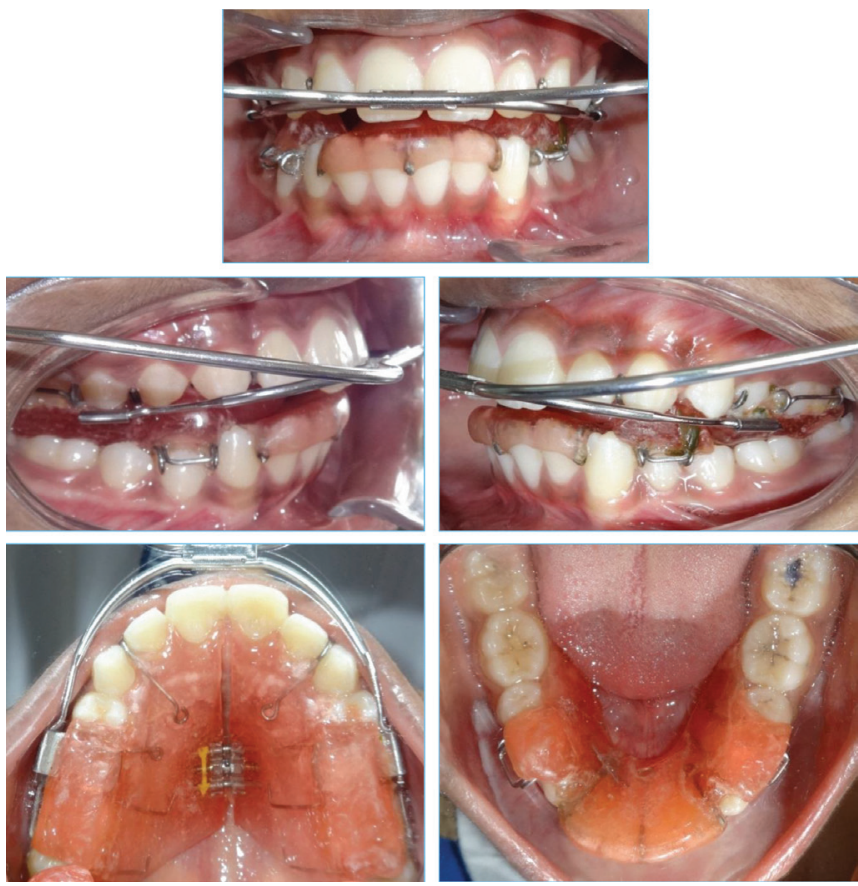

Fig. 5: Mid treatment intraoral photographs
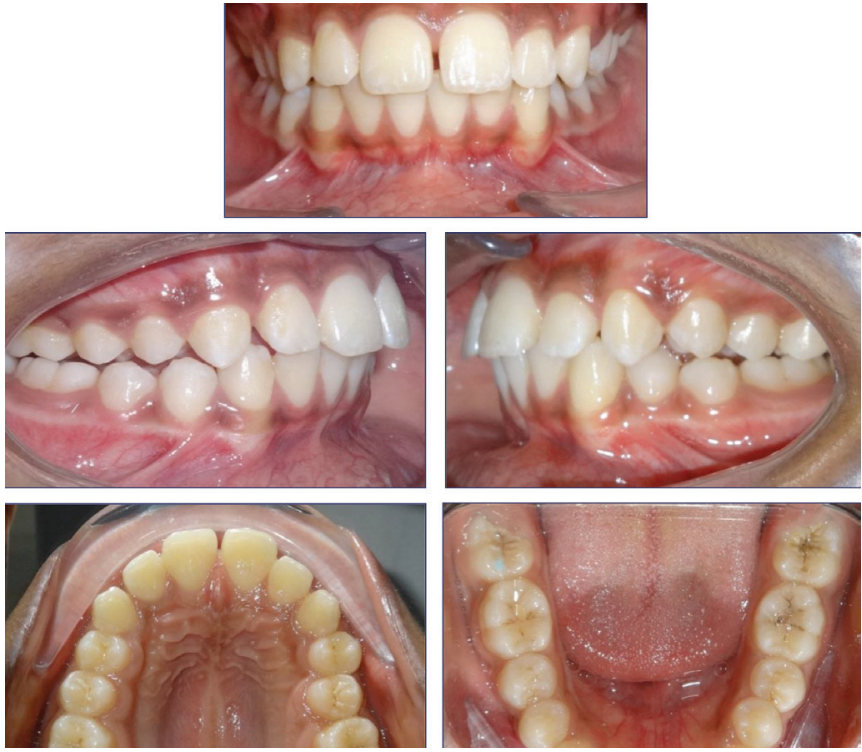

Fig. 7: Postfunctional intraoral photographs
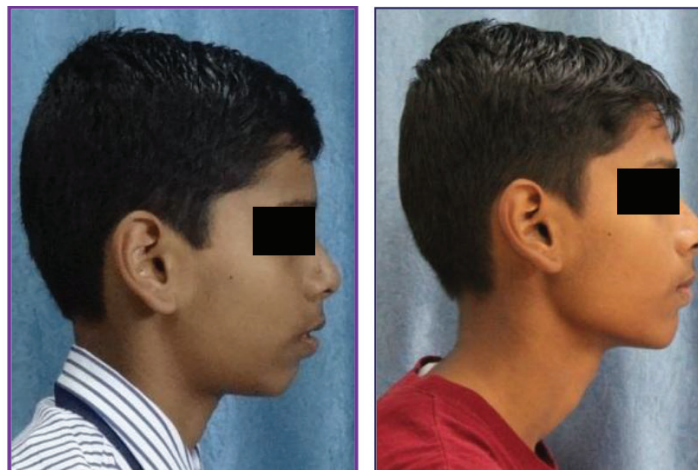

Fig. 8: Extraoral photographs (profile view) 


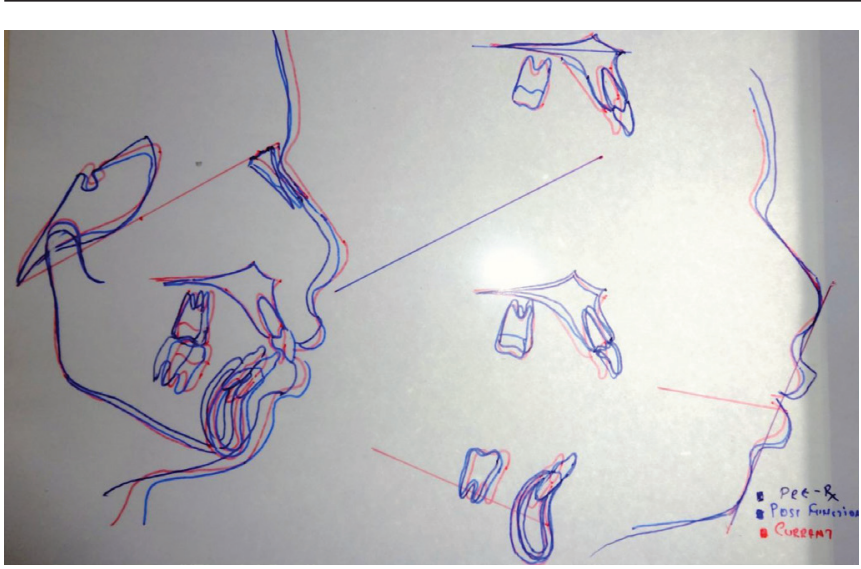

Fig. 9: Superimposition of serial lateral cephalogram using Ricketts superimposition method

improvement is as shown with superimposition of serial lateral cephalograms (Fig. 9).

\section{DISCUSSION}

Various combinations of skeletal and dental component may contribute to skeletal class II malocclusion. Therefore, identifying the etiology and understanding the expression of class II malocclusion is helpful in correcting the discrepancy and selecting the modalities of treatment, whether functional, orthodontic, and surgical or a combination of the aforementioned.

Twin block is the most commonly used removable functional appliance, based on the concept of functional occlusion, occlusion inclined plane, and proprioceptive stimulus. ${ }^{10,11}$ It enables the patient to perform masticatory function, speech, lateral excursion, and other jaw functions very comfortably; patients wear the appliance full time with little discomfort. In comparison with other functional appliances, its fabrications as well as repair are not technique sensitive and can be used in mixed dentition, deciduous dentition, and sometimes in permanent dentition. $^{12}$

Several studies have been performed and have documented the skeletal and dentoalveolar effects of twin block in tandem with extraoral traction for correction of class II malocclusion. ${ }^{13,14}$

In this case, when comparison of pretreatment and postfunctional cephalometric parameters was done, Angle between Sella, Nasion and Point A (SNA) remained the same, and Angle between Sella, Nasion and Point B (SNB) changed by $5^{\circ}$, reducing the Angle between Point A, Nasion and Point B (ANB) angle from 8 to $3^{\circ}$. Table 1 represents the cephalometric parameters before and after the twin block traction technique.

\section{CONCLUSION}

Use of twin block traction technique resulted in functional correction with restriction of maxillary growth and sagittal correction of the mandibular base.
Table 1: Cephalometric analysis

\begin{tabular}{lcc}
\hline Parameters & Pretreatment & Postfunctional \\
\hline Facial angle (FH-N-Pog) & $80^{\circ}$ & $85^{\circ}$ \\
Angle of convexity (N-A-Pog) & $14^{\circ}$ & $8^{\circ}$ \\
SNA & $79^{\circ}$ & $79^{\circ}$ \\
SNB & $71^{\circ}$ & $76^{\circ}$ \\
ANB & $8^{\circ}$ & $3^{\circ}$ \\
Upper Incisor-NA (Degree) & $27.5^{\circ}$ & $25^{\circ}$ \\
Upper Incisor-NA (mm) & $7.5 \mathrm{~mm}$ & $6 \mathrm{~mm}$ \\
Lower Incisor-NB (angle) & $33^{\circ}$ & $39^{\circ}$ \\
Lower Incisor-NB (mm) & $8 \mathrm{~mm}$ & $8 \mathrm{~mm}$ \\
BO-AO (Wits appraisal) & $+4 \mathrm{~mm}$ & $+1 \mathrm{~mm}$ \\
FMA & $27.5^{\circ}$ & $24^{\circ}$ \\
FMIA & $42.5^{\circ}$ & $46^{\circ}$ \\
IMPA & $110^{\circ}$ & $110^{\circ}$ \\
Anterior cranial base & $63 \mathrm{~mm}$ & $63 \mathrm{~mm}$ \\
length (Se-N) & & \\
Extent of maxillary base & $43 \mathrm{~mm}$ & $43 \mathrm{~mm}$ \\
(PNS-Pt. A') & & \\
Extent mandibular base & $63 \mathrm{~mm}$ & $65.5 \mathrm{~mm}$ \\
(Go-Pog) & & $0 \mathrm{~mm}$ \\
N Perp-A & $-3 \mathrm{~mm}$ & $-6 \mathrm{~mm}$ \\
N Perp to Pogonion & $-17 \mathrm{~mm}$ & $85^{\circ}$ \\
Facial Angle & $80^{\circ}$ & $+3.5 \mathrm{~mm}$ \\
Convexity at Pt. A & $+6.5 \mathrm{~mm}$ & \\
\hline
\end{tabular}

\section{REFERENCES}

1. Proffit WR, Fields HW Jr, Moray LJ. Prevalence of malocclusion and orthodontic treatment need in the United States: estimates from the NHANES III survey. Int J Adult Orthodon Orthognath Surg 1998;13(2):97-106.

2. Gelgor IE, Karaman AI, Ercan E. Prevalence of malocclusion among adolescents in central Anatolia. Eur J Dent 2007 Jul; 1(3):125-131.

3. Celikoglu M, Akpinar S, Yavuz I. The pattern of malocclusion in a sample of orthodontic patients from Turkey. Med Oral Patol Oral Cir Bucal 2010 Sep 1;15(5):e791-e796.

4. McNamara JA Jr. Components of class II malocclusion in children 8-10 years of age. Angle Orthod 1981 Jul;51(3): 177-202.

5. Karacay S, Akin E, Olmez H, Gurton AU, Sagdic D. Forsus Nitinol Flat Spring and Jasper Jumper corrections of class II division 1 malocclusions. Angle Orthod 2006 Jul;76(4): 666-672.

6. Jones G, Buschang PH, Kim KB, Oliver DR. Class II nonextraction patients treated with the Forsus Fatigue Resistant Device versus intermaxillary elastics. Angle Orthod 2008 Mar;78(2):332-338.

7. Gunay EA, Arun T, Nalbantgil D. Evaluation of the immediate dentofacial changes in late adolescent patients treated with the Forsus FRD. Eur J Dent 2011 Oct;5(4):423-432.

8. Oztoprak MO, Nalbantgil D, Uyanlar A, Arun T. A cephalometric comparative study of class II correction with Sabbagh Universal Spring (SUS(2)) and Forsus FRD appliances. Eur J Dent 2012 Jul;6(3):302-310.

9. Kharbanda OP. Diagnosis and management of malocclusion and dentofacial deformities. 2nd ed. 2013. 
10. Clark WJ. The twin block traction technique. Eur J Orthod 1982 May;4(2):129-138.

11. Clark WJ. The twin block technique. A functional orthopedic appliance system. Am J Orthod Dentofacial Orthop 1988 Jan;93(1):1-18.

12. Al-Anezi SA. class II malocclusion treatment using combined Twin Block and fixed orthodontic appliances: a case report. Saudi Dent J 2011 Jan;23(1):43-51.
13. Trenouth MJ. A comparison of twin block, Andresen and removable appliances in the treatment of class II Division 1 malocclusion. Funct Orthod 1992 Jul-Aug;9(4): 26-31.

14. Trenouth MJ. Cephalometric evaluation of the Twin-block appliance in the treatment of class II Division 1 malocclusion with matched normative growth data. Am J Orthod Dentofacial Orthop 2000 Jan;117(1):54-59. 